group comprising about seven hundred species was examined. The tests were made against the Grampositive type Staph. aureus and the Gram-negative type Bact. typhosum. Out of a total of approximately 1,100 species, about fifty showed antibacterial activity against Staph. aureus, but only four of these, namely, Drosera Whittakeri and three species of Persoonia, also affected Bact. typhosum. Substances active against both Gram-positive and Gram-negative bacteria are of special interest on account of their possible potential value in the chemotherapy of a wide range of infections. These four plants were therefore selected for more extensive examination.

The activity appeared in extracts of leaves and stems of the Drosera and in extracts of the berries of the Persoonias. Bulk extraction of the active parts of these plants was earried out, and attempts are being made to purify the active substance. Some characterization of the Persoonia substance has so far been achieved. In crude extracts, the activity was greater against Bact. typhosum than against Staph. aureus. This activity was readily destroyed by alkalinity $(p \mathrm{H} 9)$ but persisted in acid solution $(p \mathrm{H} \mathrm{2})$ for several hours at least, and was not destroyed by heating at $100^{\circ} \mathrm{C}$. for at least 45 minutes. Crude extracts kept at $4^{\circ} \mathrm{C}$. retained their activity for at least eight months. The active substance did not appear to be volatile in steam; it was absorbed by charcoal, from which it was partly recovered by elution with ethyl alcohol. Work on further purification of this material is proceeding.

The majority of the other plants active only against Staph. aureus belonged to the Myrtaceæ, a family well represented among the native Australian flora. Further investigation of Chamcelaucium uncinatum, in which activity was detected only in the flowers, and Darwinia citriodora, in which activity appeared in both flowers and leaves, located the antibacterial substance in the oil obtained by steam distillation of the active part of the plant. These oils have provolsed our interest because they exhibited antibacterial activity against $M y c o$. phlei, an acid-fast bacillus. Any material showing action against the Mycobacteria is worthy of attention; these oils are therefore undergoing fractionation with the object of isolating the active constituents.

Detailed reports of this work will appear elsewhere. NANCY AtKInson

Institute of Medical and Veterinary Science, Adelaide.

Sept. 23.

${ }^{1}$ Atkinson, N., and Rainsford, K. M., Austral. J. Exp. Biol., 24, 49 (1946).

\section{Action of Thionyl Chloride on Carboxylic Acids in Presence of Pyridine}

THE catalytic effect of small amounts of pyridine in the reaction between thionyl chloride and carboxylic acids is well known; Carré and Libermann" have shown further that it is of great advantage to use equimolar quantities of acid, pyridine, and thionyl chloride, the acid chloride then being formed rapidly at lower temperatures, in high yield. This convenient method apparently has not been very widely used, and instructions for making acid chlorides generally call for the use of excess thionyl chloride and 'a few drops' of pyridine.

Finding it necessary to prepare substituted amides from the hydrogen phthalates of secondary alcohols, we have followed a process essentially the same as that of Carré and Libermann, but have prepared and tested for the intermediate acid chlorides in solution, without attempting to isolate them. This method has given very good results, and would seem to be generally applicable to the preparation of derivatives from acids which are too unstable to withstand the action of heat or excess thionyl chloride.

In general, the acid was dissolved in ten volumes of dry solvent (ether was preferred, but benzene, chloroform or carbon tetrachloride could be used) treated with one equivalent of dry pyridine, and then exactly one equivalent of purified thionyl chloride ${ }^{2}$ was added, drop-wise with stirring. Pyridine hydrochloride separated, except when chloroform was the solvent, and the mixture was left at $15-20^{\circ}$ for an hour. The alcohol or amine to be coupled with the acid chloride was mixed with one equivalent of pyridine, and added drop-wise with stirring; then the ester or amide was recovered and purified by the usual methods. From cyclohexyl hydrogen phthalate, by the action of thionyl chloride and pyridine, followed by coupling with aniline, we obtained cyclohexyl phthalanilate, m.p. $111 \cdot 5^{\circ}$, in yields exceeding 80 per cent.

Experiments by L. H. Darling indicate that esters made by this general method may contain traces of sulphur compounds, and are unsuitable for catalytic hydrogenation.

Johnson Chemical Laboratories,

$$
\text { J. P. E. HumaN }
$$
JoHN A. MrLLs

University of Adelaide.

Oct. 31.

${ }^{1}$ Carré and Libermann, C.R. Acad. Sci., 199, 1422 (1934).

'Fieser, "Experiments in Organic Chemistry"' (Heath and Co., New York, 1935), 339.

\section{Measurement of the Photodynamic Effect of Cancerogenic Substances with Biological Indicators}

THE photodynamic effect of cancerogenic substances was examined by Mottram and Doniach ${ }^{1}$ using Paramecium. They found that the cancerogenic substances had a stronger effect than the noncancerogenic photosensitizers. We have tried to estimate the photodynamic effect of cancerogenic substances by means of a standard biological indicator, namely, the 3rd stage larvæ of Drosophila melanogaster, as it is known that they are suitable for the standardizing and measuring of radiation.

We used for the experiments a five years inbred white-eyed strain (white $4 \mathrm{ch}$. 1.5 Morgan unit). To $13 \mathrm{gm}$. standard Drosophila food we added $1 \mathrm{mgm}$. benzpyrene, methylcholanthrene or dibenzanthracene, and the imagos on this food laid eggs. The animals were in the dark. We found by fluorescence microscopy that the cancerogenic substances were in the organs and cells in a dissolved state. We radiated groups of some forty larvæ with a quartz mercury lamp (Hanau type Jubiläums Höhensonne $2.5 \mathrm{amp}$., 220 V.) from a distance of $36 \mathrm{~cm}$. at $24-26^{\circ} \mathrm{C}$. Their death was observed under these conditions, and the duration of the radiation was noted.

The control larvæ, which were bred on standard Drosophila food, died after $39 \mathrm{~min}$. 51 sec. \pm 4 min. 17 sec. The larvæ treated with benzpyrene died after 6 min. 30 sec. \pm 1 min. 15 sec.; with methylcholanthrene after $13 \mathrm{~min} .35$ sec. $\pm 1 \mathrm{~min} .57 \mathrm{sec}$; 